\title{
Family Planning Knowledge and Practices among Women in a District Hospital
}

\author{
Gupta S, ${ }^{1}$ Singh A, ${ }^{1}$ Gupta N, ${ }^{2}$ Shrestha $\mathrm{VL}^{3}$ \\ 'Lamjung District Hospital, Besisahar, Lamjung, Nepal, ${ }^{2}$ National Open College, Sanepa, Kathmandu, Nepal, ${ }^{3}$ Nobel Col- \\ lege, Sinamangal, Kathmandu, Nepal.
}

Introduction: Family planning services have the potential to improve the quality of the lives of people. The study was done to assess the family planning practice and methods among the married women of reproductive age attending female clinic of district hospital of Nepal.

Methods: This is a cross sectional descriptive study carried out from October 2011 till December 2011 at Lamjung district hospital. One hundred randomly selected married women of 15-49 years, who had at least one child were the subjects of the study. A structured questionnaire on knowledge, practice and methods of use of contraception was composed and filled up.

Results: The results were encouraging with 94 (94\%) of participants having knowledge about contraception. The study showed that 32 (32\%) of the married women belonged to 20-24 years of age group. Among them 64 (68\%) were using modern contraception methods. Injectables hormonal contraceptives were most commonly practiced by 34 (54\%) women. Among not using any contraceptives, 18 $(60 \%)$ of them said their husband being abroad.

Conclusions: Family planning knowledge and practice among the rural women utilizing the service was appreciable. Temporary method of contraception was most commonly practiced.

Keywords: district hospital; knowledge; practice, family planning.

\section{INTRODUCTION}

Reproductive Health is a state of complete physical, mental and social wellbeing and not merely the absence of disease or infirmity, in all matters relating to the reproductive system and to its functions and processes. This implies that given peoples capability to reproduce they have the freedom to decide it, when and how to do so. Women and men therefore have the right to be informed and have access to safe, affordable and effective methods of family planning of their choice as well as other methods of fertility regulation.

Family planning services can be an important and effective first step to reduce maternal deaths in developing countries. Fewer unwanted pregnancies mean fewer pregnancy related deaths, making family planning a vital way to improve maternal health. ${ }^{1}$ The Total Fertility Rate (TFR) decreased from 6.3 in 1976 to 3.1 in 2006. In the same period, the contraceptive prevalence rate increased from $2.9 \%$ to $48 \%$. In addition the maternal mortality rate declined from 539 in 1996 to 281 in 2006, and much of this decline was attributed to increase use of family planning, information, education and communication campaigns have successfully increased knowledge of family planning methods. ${ }^{2}$

The study of Mustafa R. et al conducted among rural women of Pakistan found that there was low contra-

Correspondence: Dr. Sandeep Gupta, Lamjung District Hospital, Besisahar, Lamjung, Nepal. Email: sandeep140@hotmail.com, Phone: 9841388684 
ceptive use among women of rural origin despite good knowledge. In the study the main source of awareness for family planning was from media. Only $53 \%$ of interviewed women were practicing family planning methods. ${ }^{3}$ A study from Kathmandu showed that $93 \%$ of participants were aware of at least one family planning methods but only $65 \%$ had ever used it and contraceptive prevalence rate was $33.5 \% .^{1}$ The most commonly known method was depo provera followed by oral contraceptive pills. ${ }^{1}$

\section{METHODS}

This is a cross sectional descriptive study carried out in collecting quantitative data from married women of reproductive age group of 15-49 years visiting Lamjung District Hospital female clinic. The duration of study was from October 2011 till December 2011.

An ever married woman of 15- 49 years who had at least one child were the subjects of study and were randomly selected among the women attending the outpatient clinic of the hospital. A structured questionnaire was composed on knowledge, practice and methods of use of contraception. The questionnaire was then used to conduct structured interviews with women in the clinic at Lamjung District Hospital.

The study was approved by the Internal Management Committee of the hospital and verbal consent was taken from each participants. The participants were informed that the participation in the study will be voluntary and that they could end at anytime. The data thus collected was compiled, analyzed in Microsoft excel software.

\section{RESULTS}

There were total of 100 participants in the study. It is encouraging to know that the level of knowledge among the women about family planning practice was $94 \%$. Sixty eight percentage of women were using a modern method of contraception and thirty two percent were not using any method of contraception (Figure. 1).

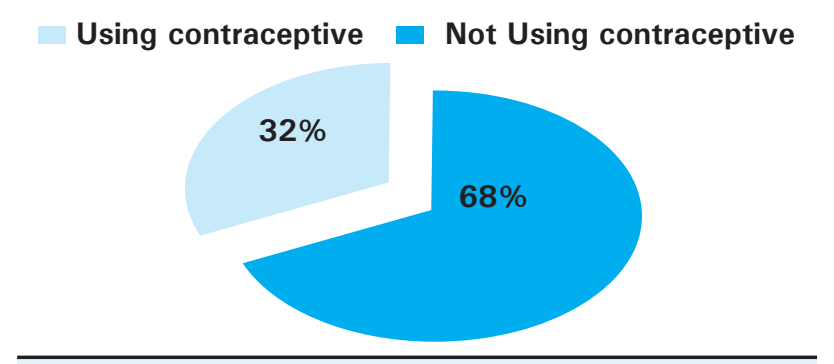

Figure 1. Distribution of use of contraception

Distribution of use of contraception
The age in years of the participants varied from 16 to 42. In the study group $32 \%$ of women belonged to 20 24 years age group, followed by $30 \%$ in the age group of 25-29 years (Figure 2).

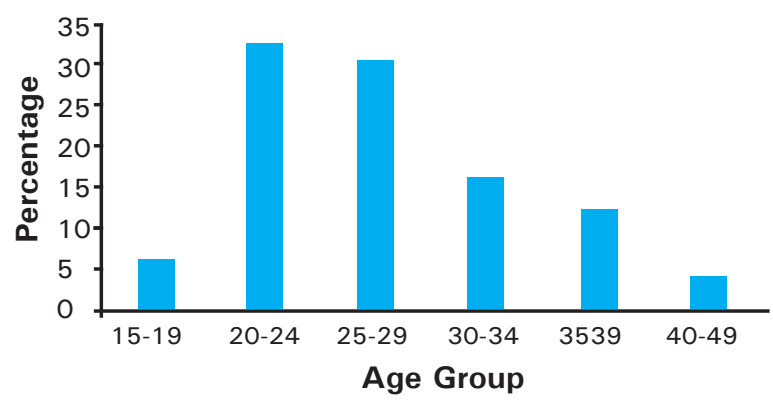

Figure 2. Distribution of participants as per age group

More than half $34(54 \%)$ of women were using injectable contraceptives. Oral pills were used by $18(28 \%)$ of women. Permanent female sterilization was done by $8(12.5 \%)$ of women (Table 1$)$.

Table 1. Utilization of Contraception

\begin{tabular}{ll}
\hline Types of Contraception & $(\mathrm{n}=64)(\%)$ \\
\hline Oral Pills & $18(28 \%)$ \\
Injectable Contraceptive & $34(54 \%)$ \\
IUCD & $4(6.2 \%)$ \\
Sterelization & $8(12.5 \%)$ \\
\hline
\end{tabular}

In distribution of reason for not using any contraception one third $10(33.3 \%)$ opined that they wish to extend their family. Sixty percentage of women did not use any contraception because of their husbands being abroad (Table 2).

Table 2. Distribution of Reason for not Using any Method of Contraception

\begin{tabular}{ll}
\hline \multicolumn{1}{c}{ Reasons } & $\begin{array}{l}\text { Participants (\%) } \\
\text { (n= 30) }\end{array}$ \\
\hline Wish to have more children & $10(33.3 \%)$ \\
Husband abroad & $18(60 \%)$ \\
Male sterilization & $1(3.3 \%)$ \\
No response & $1(3.3 \%)$ \\
\hline
\end{tabular}

\section{DISCUSSION}

Family Planning is defined by WHO as "a way of think- 
ing and living that is adopted voluntarily, upon the basis of knowledge, attitudes and responsible decisions by individuals and couples, in order to promote the health and welfare of family groups and thus contribute effectively to the social development of a country.

Acceptance of family planning largely depends on knowledge and awareness of family planning methods. Knowledge of contraception methods is an important precursor to their use. The five year development programme of Nepal has aim towards a decentralised reproductive health programme that will increase the utilisation of quality reproductive health services by women, men and adolescents whilst also increasing awareness of reproductive health risks and benefits. This latter initiative has the goal of brining about behavioural changes regarding safer sex and reproductive practices. $^{4}$

The present study aimed to assess the knowledge and practice of family planning methods among the women of rural district of Nepal. Results showed that knowledge of contraception was $94 \%$ as compared to $93 \%$ in study conducted at Kathmandu. ${ }^{1}$ In a study conducted in Pakistan and India, knowledge of contraception was $81 \%$ and $82.2 \%$ respectively. ${ }^{3,5} \mathrm{~A}$ study from rural part of our country has reported an exposure to electronic media messages as main factor for use of family planning methods among women. ${ }^{6}$

In the present study only $68 \%$ of the interviwed women were practicing family planning methods, the result was high then the study conducted in rural part of $\mathrm{Pa}$ kistan were only $53 \%$ were practicing any one fam- ily planning methods. In study of Kumar et al $66.5 \%$ were using a method of contraception among women of urban slums of Lucknow city. ${ }^{7}$ Regarding the usage of family planning methods, an important dimension is the type of contraceptive used. Temporary method of contraception was more commonly preferred. Injectable contraceptive was used by $54 \%$ of women followed by oral pilles by $18 \%$ and IUCD by $6.2 \%$ and $12.5 \%$ of women were sterlised. The result was similar on preferance of using temporary method of choice by the women of kathmandu. Injectable contraceptive was practiced by $78 \%$ and folowed by oral pills by $74 \%{ }^{1}$ The study of Kumar et al showed $36.6 \%$ of women preferred oral pills followed by sterilization by $24.3 \%$. $^{7}$ The study of Mustafa R. et al conducted among rural women of Pakistan, the most common chosen method used by $33.9 \%$ followed by $11.3 \% .^{3}$

Women not practicing contraception in our study was $32 \%$, other studies of Srivastava $\mathrm{R}$ et al and Prachi $\mathrm{R}$ et al showed that non use of contraception was $55 \%$ and $44.6 \% .5,8$ The most common reason for not using contraception was husband being abroad followed by wish to extend family.

\section{CONCLUSION}

The study reveals good knowledge and practice of rural women towards contraception but still needs improvement. Continuous effort is needed from the government and local community to educate the public about the safety and convenience of modern, long term and reversible methods of contraception.

\section{REFERENCE}

1. Tuladhar H, Marahatta R. Awareness and Practice of Family Planning methods in women attending Gyncology OPD at Nepal Medical College Teaching Hospital. Nepal Med Coll J 2008;10(3):184-91.

2. Nepal Demographic \& Health Survey (NDHS) 2006. Population Division, Ministry of Health, Government of Nepal, Kathmandu, Nepal 2006.

3. Mustafa R, Afreen U, Hashmi HA. Contraceptive Knowledge, Attitude and Practice Among Rural Women. J Coll Physician Surg Pak. 2008;18(9):542-45

4. Uprety S, Jha N,Poudel IS. Impact and Determinants of Gender Preference in Duhavi VDC of Eastern Nepal. J Nepal Med Assoc. 2011;51(181):28-33.
5. Srivastava R, Srivastava DK, Jina R, Srivastava K, Sharma N, Sana S. Contraceptive Knowledge, Attitude and Practice. J Obstet Gynecol India. 2005;55:546-50.

6. Boulay M, Sotrey JD, Sood S. Indirect exposure to a family planning mass media Campaign in Nepal. J Health Commun. 2002;7:379-99.

7. Kumar A, Bharadwaj P, Srivastava JP, Gupta P. A Study on family Planning Practices and Methods among women of Urban slums of Lucknow city. Ind J Comn Hlt. 2011;23(2):75-7.

8. Prachi R, Das GS, Ankur B, Shipra J, Binita K. A Study of Knowledge, Attitude and Practice of Family Planning among the women of reproductive age group in Sikkim. J obstet Gyneco India. 2008;58:63-67. 